\title{
Access to Primary Care Appointments Following 2014 Insurance Expansions
}

\author{
Karin V. Rbodes, $M D, M S^{1,2,3}$ \\ Simon Basseyn, $B A^{2,3,4}$ \\ Ari B. Friedman, $M D, P b D^{5}$ \\ Genevieve M. Kenney, $P b D^{6}$ \\ Douglas Wissoker, $\mathrm{PbD}^{6}$ \\ Daniel Polsky, $\mathrm{PbD}^{2,3,4}$ \\ 'Northwell Health, Offfice of Health \\ Management/Hofstra Northwell School of \\ Medicine, Great Neck, New York \\ ${ }^{2}$ Perelman School of Medicine, Philadel- \\ phia, Pennsylvania \\ ${ }^{3}$ Leonard Davis Institute of Health Econom- \\ ics, Philadelphia, Pennsylvania \\ ${ }^{4}$ The Wharton School, Philadelphia, \\ Pennsylvania \\ ${ }^{5}$ Beth Israel Deaconess Medical Center, \\ Department of Emergency Medicine, Bos- \\ ton, Massachusetts \\ ${ }^{6}$ The Urban Institute, Washington, DC
}

Conflicts of interest: authors report none.

\section{CORRESPONDING AUTHOR}

Karin Rhodes, MD, MS

Northwell Health, Office of Population

Health Management

Hofstra Northwell Medical School

600 Community Dr, Rm 423

Manhasset, NY 11030

krhodes@northwell.edu

\begin{abstract}
PURPOSE The Patient Protection and Affordable Care Act (ACA) expanded coverage to roughly 12 million individuals by mid-2014 and 20 million by 2016, raising concern about the capacity of the primary care system to absorb these individuals. We sought to determine whether there was an empirical basis for these concerns.
\end{abstract}

METHODS We used an audit design in which simulated patients called primary care practices seeking new-patient appointments in 10 diverse states (Arkansas, Georgia, lowa, Illinois, Massachusetts, Montana, New Jersey, Oregon, Pennsylvania, and Texas) from November 2012 through April 2013 and from May 2014 through August 2014, before and after the major ACA insurance expansions. Callers were randomly assigned to scripts specifying either private or Medicaid insurance and called only offices identified as "in network" for each plan.

RESULTS We completed 5,385 private insurance and 4,352 Medicaid calls in 2012-2013 and 2,424 private insurance and 2,474 Medicaid calls in 2014. Overall appointment rates for private insurance remained stable from 2012 (84.7\%) to 2014 (85.8\%) with Massachusetts and Pennsylvania experiencing significant increases. Overall, Medicaid appointment rates increased 9.7 percentage points (57.9\% to $67.6 \%$ ) with substantial variation by state. Median wait-times for callers obtaining a new patient appointment remained unchanged at 6 days for privately insured but rose from 6 days to 7 days for Medicaid callers.

CONCLUSIONS Contrary to widespread concern, we find no evidence that the millions of individuals newly insured through the ACA decreased new-patient appointment availability across 10 states as shown by stable wait times and appointment rates for private insurance as of mid-2014.

Ann Fam Med 2017;15:107-112. https://doi.org/10.1370/afm.2043.

\section{INTRODUCTION}

A ccording to the Congressional Budget Office and the National Health Interview Survey, the number of adults with health insurance coverage increased by approximately 12 million between the 2012 passage of the Patient Protection and Affordable Care Act (ACA) and mid-2014, while the uninsured rate decreased to $12.2 \%{ }^{1,2}$ as a result of the insurance expansions under the ACA. Because insurance coverage lowers the out-of-pocket cost of care, it has been projected that these expansions could lead to a $14 \%$ increase in demand for primary care. ${ }^{3}$ The number of newly covered individuals reaching 20 million by early $2016^{4}$ raises concerns about whether the primary care system can absorb the millions of new patients seeking care..$^{5-7}$ In this study, we sought to identify changes in the proportion of primary care providers with appointment availability before and after the major ACA insurance expansions in late 2012/early 2013 and mid-2014, respectively. The data came from an audit design in which primary care offices were asked to provide appointments to simulated patients before and during the implementation of the ACA. This approach allows for tracking trends in primary care appointment availability, while holding the clinical scenario and caller details constant, and experimentally varying the insurance status. 


\section{METHODS}

Trained field staff with phone voices that corresponded to different ages, sexes, and race/ethnicities called primary care practices seeking new-patient primary care appointments with either private or Medicaid insurance. Calls were made in 2 waves: November 2012April 2013 and May 2014-July 2014. The 2nd wave was conducted just months after the first open enrollment period closed under the ACA. Practices called were located in Arkansas, Georgia, Iowa, Illinois, Massachusetts, Montana, New Jersey, Oregon, Pennsylvania, and Texas. These 10 states were selected for geographic and health system diversity. Note that Massachusetts uniquely instituted mandatory individual health insurance coverage in 2006 while the other 9 states did not have this requirement until the ACA's insurance expansion provisions were enacted in 2014. Massachusetts, therefore, represents a unique case, and results should be interpreted with this key difference in mind.

Physician offices were randomly selected from all offices in the state that provide primary care to workingage adults, from a frequently updated commercial database. ${ }^{8}$ Callers named a specific private or Medicaid insurance plan-typically the plan with the largest market share in that county-previously identified as accepted by the office in a non-deceptive pre-audit phone survey. Callers were to request the earliest available appointment from an identified physician in that office either for a routine appointment or urgent care visit for newly diagnosed untreated hypertension. If the requested physician was unavailable or the wait-time was longer than 4 weeks for the routine scenario or 2 weeks for the urgent scenario, the callers accepted appointments with any available clinician, including nurse practitioners and physician assistants. Each appointment was canceled at the end of the call.

We considered an appointment affirmatively scheduled if the caller was offered a specific date and time or was told that the specific appointment would be scheduled when the caller called back with an insurance number. Appointments were considered denied if the caller was told that no appointment was available. Cases with vague appointment availability or appointment system restrictions were excluded. The sample frame, methodology, and sample for the first wave have been described in greater detail elsewhere. ${ }^{9}$

We have previously reported on increases in Medicaid appointment availability associated with the ACA's temporary increases in primary care Medicaid reimbursements ("fee bump"). ${ }^{10}$ The sample we used, however, did not include Federally Qualified Health Centers (FQHCs), as FQHCs were excluded from the ACA's "fee bump" provision. The sample reported in this paper does include FQHCs.
Our primary outcomes were mean appointment rates, derived using weights based on the proportion of the state population with each insurance plan available in the county of the practice called. Ten-state averages are based on a simple average across the states with statistical significance of differences assessed by weighted linear probability model regression clustered by county. Our secondary outcome was the median wait-time in calendar days to appointments, with statistical significance assessed by weighted quantile regression. Statistical significance was determined at the $P$ $<0.05$ level. Our unit of analysis was a primary care

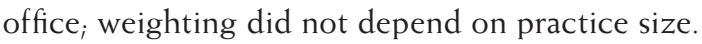

\section{RESULTS}

We completed 5,385 private insurance and 4,352 Medicaid calls in 2012-2013, and 2,424 private insurance and 2,474 Medicaid calls in 2014 (Table 1). By design, caller characteristics and clinical scenarios were distributed uniformly. Because there were no significant differences between the routine and urgent care scenarios, all analyses combine data from the 2 .

We found that new-patient appointment rates for privately insured callers remained stable in these 10 states between 2012 (84.7\%) and 2014 (85.8\%) (Figure 1). While no state experienced a significant decrease in new-patient appointment rates for privately insured patients, 2 states-Massachusetts and Pennsylvania-saw significant increases of 10.5 percentage points and 9.7 percentage points, respectively. Only 2 of the 10 states had 2014 appointment rates significantly different from the 10 -state average. Montana's appointment rate was 8.4 percentage points higher, and Oregon's was 16.9 percentage points lower.

In contrast, we found increases in new patient access to primary care appointments for Medicaid patients across all of the 10 study states, with an overall increase from $57.9 \%$ to $67.6 \%$ (Figure 2). Across all states, median wait times in calendar days for privately insured callers obtaining an appointment were 6 days both in 2012-2013 and in 2014 while median wait times for Medicaid were 6 days in 2012-2013 and 7 days in 2014 (difference not significant). Wait times for private insurance and Medicaid for the 2 call waves shown in Figures 3-4.

\section{DISCUSSION}

Despite widespread concerns that the influx of millions of individuals newly insured through Medicaid and the marketplaces would strain the primary care system, we find no evidence of such as of mid-2014, as evidenced by the stability in appointment rates and wait-times for new privately insured patients and an increase in 
appointment access for new Medicaid patients in our 10 study states. Our findings are consistent with results of a 2015 Michigan study that also used simulated patient methodology ${ }^{11}$ and of a recent household survey that found a lower overall prevalence of clinician access problems in 2014 than in $2013 .^{12}$

There are a number of potential explanations for our not finding a decline in primary care availability in our study despite the millions of newly insured. Notably, as of mid-2014, there may indeed have been sufficient capacity within the primary care system to absorb new patients. This was suggested by our 2012 baseline data, from before the ACA's insurance expansions, where appointment rates were nearly $85 \%$

Table 1. Sample Size, Month of Call, and Caller Characteristics by Call Wave

\begin{tabular}{|c|c|c|c|c|}
\hline & \multicolumn{2}{|c|}{$\begin{array}{l}\text { First call wave } \\
(2012-2013)\end{array}$} & \multicolumn{2}{|c|}{$\begin{array}{l}\text { Second call wave } \\
(2014)\end{array}$} \\
\hline & Private & Medicaid & Private & Medicaid \\
\hline \multicolumn{5}{|l|}{ Sample sizes, No. } \\
\hline 10 States & 5,385 & 4,352 & 2,424 & 2,474 \\
\hline Arkansas & 418 & 249 & 250 & 248 \\
\hline Georgia & 634 & 517 & 261 & 293 \\
\hline Illinois & 632 & 596 & 266 & 281 \\
\hline lowa & 383 & 373 & 250 & 261 \\
\hline Massachusetts & 905 & 714 & 228 & 251 \\
\hline Montana & 124 & 108 & 121 & 120 \\
\hline New Jersey & 637 & 478 & 278 & 278 \\
\hline Oregon & 414 & 296 & 244 & 212 \\
\hline Pennsylvania & 582 & 540 & 255 & 267 \\
\hline Texas & 656 & 481 & 271 & 263 \\
\hline \multicolumn{5}{|l|}{ Month of call, No. } \\
\hline Jan & 1,801 & 1,562 & 0 & 0 \\
\hline Feb & 890 & 723 & 0 & 0 \\
\hline Mar & 218 & 115 & 0 & 0 \\
\hline Apr & 4 & 0 & 0 & 0 \\
\hline May & 0 & 0 & 1,805 & 583 \\
\hline Jun & 0 & 0 & 595 & 1,546 \\
\hline Jul & 0 & 0 & 24 & 339 \\
\hline Aug & 0 & 0 & 0 & 6 \\
\hline Sep & 0 & 0 & 0 & 0 \\
\hline Oct & 0 & 0 & 0 & 0 \\
\hline Nov & 848 & 657 & 0 & 0 \\
\hline Dec & 1,624 & 1,295 & 0 & 0 \\
\hline Hypertension scenario, \% & 50.9 & 50.4 & 49.8 & 49.9 \\
\hline Female caller, \% & 50.6 & 49.4 & 51 & 54.4 \\
\hline \multicolumn{5}{|l|}{ Race/ethnicity of caller, \% } \\
\hline White & 39.5 & 36.8 & 43 & 45.6 \\
\hline Black & 37.9 & 38.9 & 42.3 & 41.4 \\
\hline Hispanic & 22.6 & 24.3 & 14.7 & 13.1 \\
\hline \multicolumn{5}{|l|}{ Age of caller, \% } \\
\hline Age $18-29$ & 22.1 & 22.7 & 24.8 & 24.8 \\
\hline Age $30-44$ & 51.0 & 50.5 & 47.8 & 45.8 \\
\hline Age $45-64$ & 26.9 & 26.8 & 27.4 & 29.4 \\
\hline
\end{tabular}

for new privately insured patients, with median wait times of about 1 week. ${ }^{9}$ Alternatively, practices may be increasing the supply of primary care by reorganizing the way they provide care. The Patient-Centered Medical Home (PCMH) model, for example, encourages a team-based approach to care with greater accessibility for patients through extended after-hours or weekend care, although early results concerning the effects of PCMHs have been mixed. ${ }^{13-16}$ If primary care practices are indeed adding mid-level clinicians such as nurse practitioners and physician assistants, social workers, health educators, and behavioral health consultants, this might be expanding primary care capacity. This possibility is supported by recent results from a similar audit study in Michigan, which found that 1 year after Medicaid expansions, a greater proportion of new-patient appointments were scheduled with mid-level clinicians. ${ }^{17}$ It is also possible that electronic medical records and asynchronous communication with patients and specialists are helping primary care clinicians care for more patients. An increase in telephone and e-mail communications between primary care clinicians and patients could also result in less need for in-person visits for existing patients and more availability of new-patient appointments. Other trends in care reorganization such as Accountable Care Organizations, alternative payment arrangements, and practice mergers might also be providing some economy of scale resulting in increased capacity.

A less rosy view is that clinicians may simply be seeing more patients in a given day. If this is the case, the added patient load may be contributing to the increasing primary care physician dissatisfaction and burnout that has been widely discussed, ${ }_{1}^{18,19}$ and that may portend an unsustainable future for primary care.

In addition, it is possible that the increase in demand for care from the insurance expansions may have been offset to some extent by decreases in demand following the recession. If so, when demand picks up across the economy, we may see more pressure on supply. Potential increases in demand may also be offset by trends towards higher out-of-pocket payments for patients. A recent survey of employer-sponsored health insurance found significant trends towards greater cost-sharing. Specifically, $81 \%$ of cov- 
ered workers in 2015 had a general annual deductible compared with $55 \%$ in 2006. Moreover, nearly $25 \%$ of covered workers were in high-deductible plans, up from $13 \%$ in 2010 . For all covered workers, the average deductible has increased $67 \%$ since 2010 and 255\% since $2006 .{ }^{20}$ As point-of-care costs increase, patients may be less likely to use health care resources and schedule appointments. This has been previously raised in the literature, ${ }^{21}$ and a recent study has shown that when 1 self-insured firm switched to high-deductible

Figure 1. Appointment rates for private insurance, by call wave.

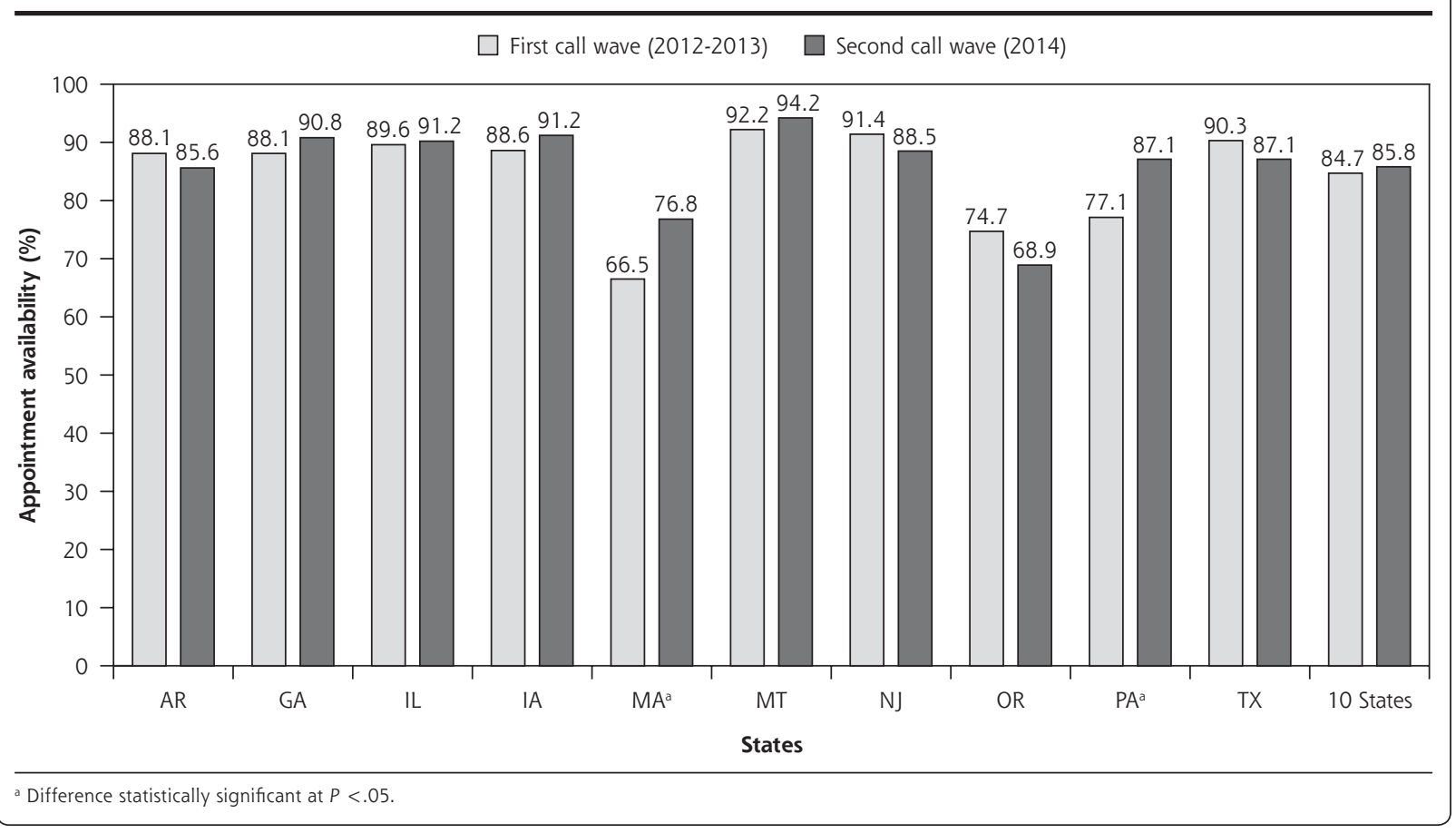

Figure 2. Appointment rates for Medicaid, by call wave.

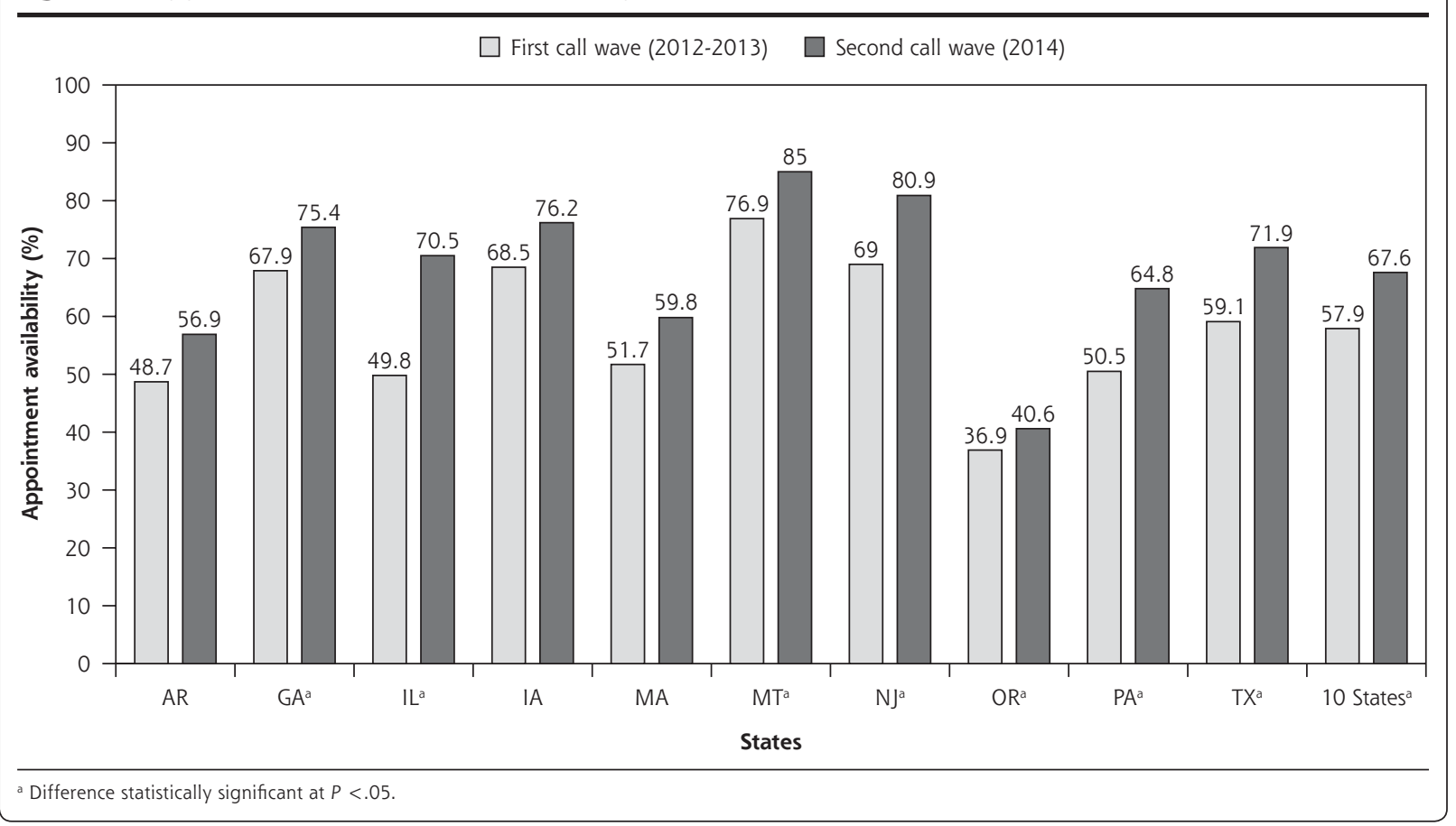




\section{Figure 3. Wait times (calendar days to appointment) for private insurance, by call wave.}

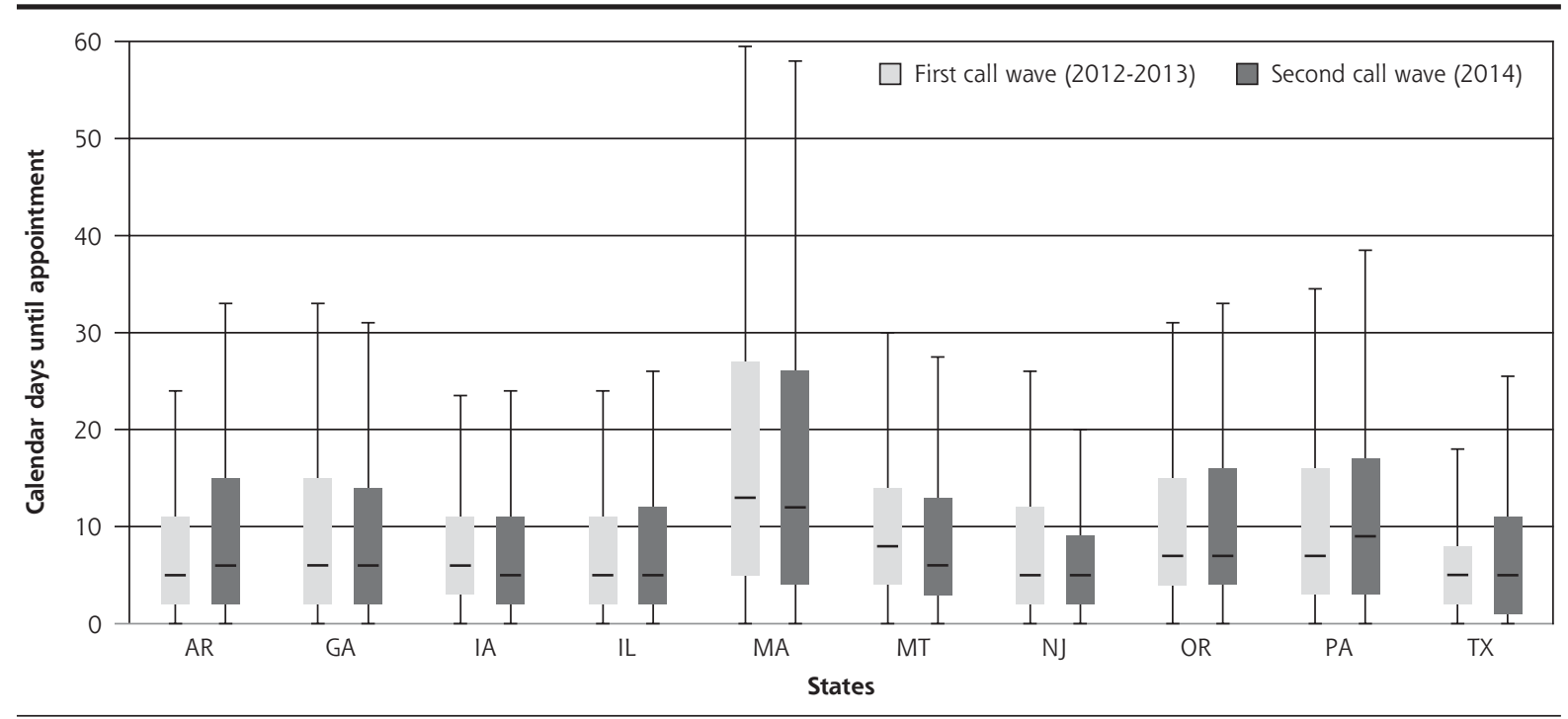

Note: Horizontal lines in boxes represent median interval days to appointment. Upper and lower edges of boxes represent the 75 th and 25 th percentiles, respectively. Upper and lower ends of whiskers represent maxima and minima after exclusion of outliers. In keeping with standard practice, outliers were determined to be values $>$ or $<1.5$ times the interquartile range above the upper and lower quartile, respectively.

Figure 4. Wait times (calendar days to appointment) for Medicaid, by call wave.

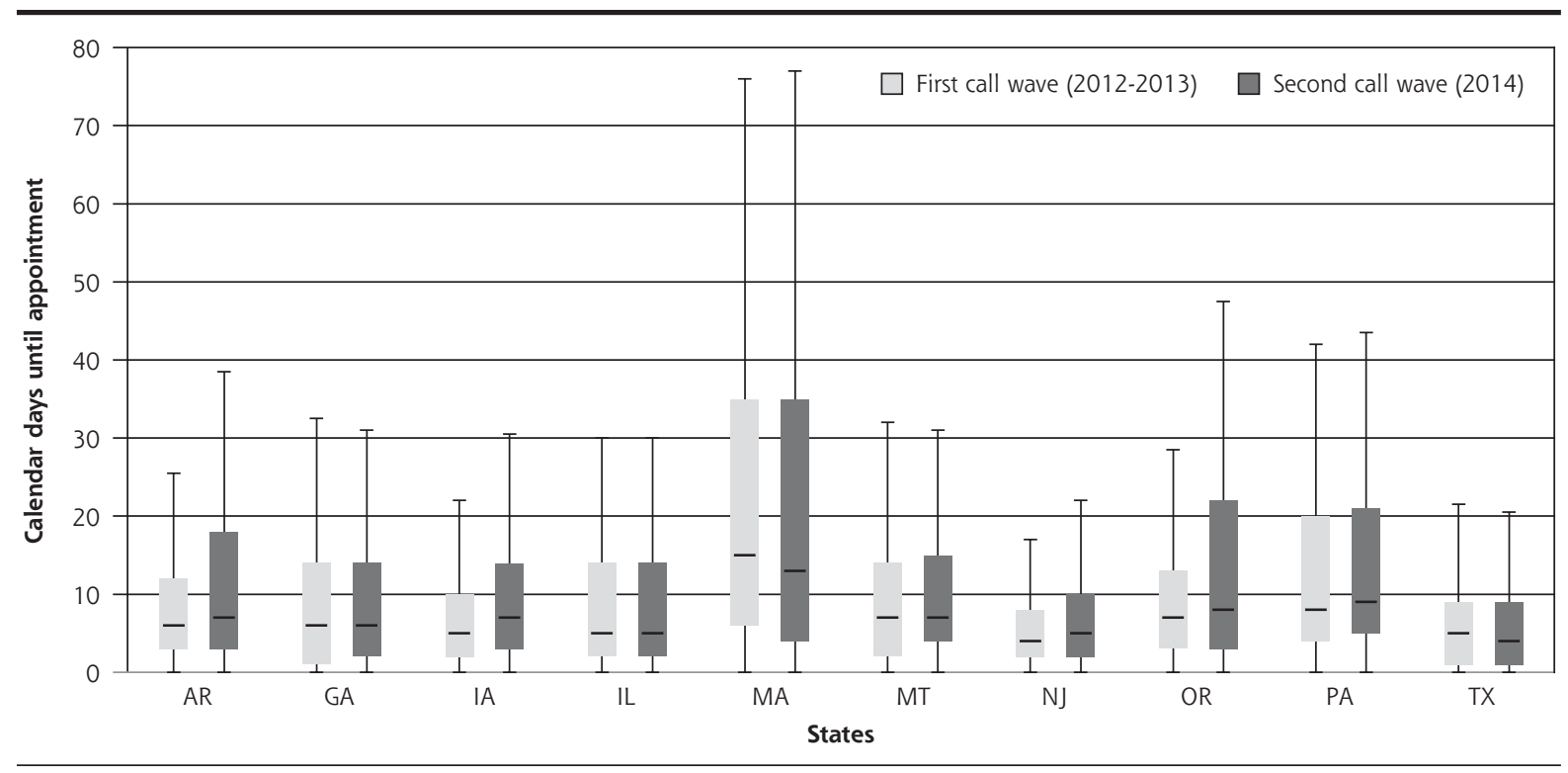

Note: Horizontal lines in boxes represent median interval days to appointment. Upper and lower edges of boxes represent the 75 th and 25 th percentiles, respectively. Upper and lower ends of whiskers represent maxima and minima after exclusion of outliers, determined as above.

plans, use of preventive services dropped by $10 \%$, and physician visits decreased by $18 \% .{ }^{22}$ Finally, mid-2014 may have been too early to see sufficient demand pressure resulting from the insurance expansions. Having health insurance is often a prerequisite to seeking care, yet many of the newly insured may not yet have accessed the primary care system to schedule appointments in our study's time period of May 2014-July 2014.
These are all plausible explanations for our findings of stability in wait times as well as stability, and even some increases in appointment rates as of mid-2014, however further research is needed to determine the true drivers.

Several limitations warrant caution in the interpretation of our results. First, seasonal variation may be playing a role, as our baseline 2012 data were collected 
in the winter months while 2014 data were collected in the spring and summer. Second, our study addresses access to primary care appointments only for new patients, not the impact of increased enrollment on access for patients who already have a source of primary care. Third, we only studied 10 states, and results may not be generalizable to other states. Fourth, while we evaluate new patient appointment rates for private insurance and Medicaid, our results do not necessarily pertain to Medicare patients, nor to patients with Marketplace plans, which may have narrower provider networks and lower reimbursement rates. Fifth, we typically assessed private appointment availability using the names of insurance plans with the largest market share, so results may not be representative of new-patient access with smaller insurance plans that may have narrow networks. Finally, although we present our results at the state level, there is likely significant geographic variation in appointment rates and wait times within states that could impact the relevance of our findings for patients in certain regions.

Although we did not find evidence of strained primary capacity for new patients despite the influx of millions of newly insured individuals as of mid-2014, it will be important to continue tracking appointment availability and wait-times in primary care as the fraction of the population with health coverage continues to change and as those who have recently gained coverage have more opportunity to seek out and use primary care and other types of health services.

To read or post commentaries in response to this article, see it online at http://www.annfammed.org/content/15/2/107.

Key words: health service accessibility; waiting lists; primary care capacity; simulated patient studies; audit methodology; health care reform

Submitted February 14, 2016; submitted, revised, July 19, 2016; accepted August 16, 2016.

Funding support: Robert Wood Johnson Foundation Grant \# 71100.

Acknowledgments: The authors acknowledge the intellectual contributions and feedback on study design and results of Katherine Hempstead PhD, Brendan Saloner PhD, and Michael Richards PhD, and the diligence in study implementation, and data collection of Martha Van Haitsma PhD, Tiana Pyer-Pereira, David Chearo, and the field staff at the University of Chicago Survey Lab.

\section{References}

1. Congressional Budget Office. Updated Estimates of the Effects of the Insurance Coverage Provisions of the Affordable Care Act, April 2014. http://www.cbo.gov/sites/default/files/cbofiles/ attachments/45231-ACA_Estimates.pdf.

2. Martinez ME, Cohen RA. Health Insurance Coverage: Early Release Estimates from the National Health Interview Survey January-June 2014. The Centers for Disease Control National Health Interview Survey Early Release Program. http://www.cdc.gov/nchs/data/nhis/ earlyrelease/insur201412.pdf.
3. Health Resources and Service Administration. Projecting the Supply and Demand for Primary Care Practitioners Through 2020, November 2013 https://bhw.hrsa.gov/health-workforce-analysis/primarycare-2020/. Accessed Apr 24, 2015.

4. Uberoi N, Finegold K, Gee E. Health Insurance Coverage and the Affordable Care Act, 2010-2016. ASPE Issue Brief, March 32016. https://aspe.hhs.gov/sites/default/files/pdf/187551/ACA2010-2016.pdf.

5. Huang ES, Finegold K. Seven million Americans live in areas where demand for primary care may exceed supply by more than 10 percent. Health Aff (Millwood). 2013;32(3):614-621.

6. Kirch DG, Henderson MK, Dill MJ. Physician workforce projections in an era of health care reform. Annu Rev Med. 2012;63(1):435-445.

7. Klein S. Strengthening the primary care workforce to meet population needs. The Commonwealth Fund: Quality Matters. http:// www.commonwealthfund.org/publications/newsletters/qualitymatters/2011/april-may-2011/in-focus. Published 2011.

8. SKEA. Databases and List Finder. http://www.skainfo.com/ databases\#physicians. Accessed Jun 232016.

9. Rhodes KV, Kenney GM, Friedman AB, et al. Primary care access for new patients on the eve of health care reform. JAMA Intern Med. 2014;174(6):861-869.

10. Polsky DE, Richards MR, Basseyn S, et al. Appointment availability after the increase in Medicaid fees for primary care. N Eng J Med, 2015;372(6):537-45.

11. Tipirneni R, Rhodes KV, Hayward RA, Lichtenstein RL, Reamer EN, Davis MM. Primary care appointment availability for new Medicaid patients increased after Medicaid expansion in Michigan. Health Aff (Millwood). 2015;34(8):1399-1406.

12. Karpman M, Weiss A, Long SK. QuickTake: Access to Health Care Providers Improved Between September 2013 and September 2014. Health Reform Monitoring Survey, February 4 2015. http://hrms. urban.org/quicktakes/Access-to-Health-Care-Providers-Improved.html.

13. Rosenthal TC. The medical home: growing evidence to support a new approach to primary care. J Am Board Fam Med. 2008;21(5): 427-440.

14. Hoff T, Weller W, DePuccio M. The patient-centered medical home: a review of recent research. Med Care Res Rev. 2012;69(6):619-644.

15. Peikes D, Zutshi A, Genevro JL, Parchman ML, Meyers DS. Early evaluations of the medical home: building on a promising start. Am J Manag Care. 2012;18(2):105-116.

16. Jackson GL, Powers BJ, Chatterjee R, et al. Improving patient care. The patient centered medical home. A Systematic Review. Ann Intern Med. 2013;158(3):169-178.

17. Tipirneni R, Rhodes KV, Hayward RA, et al. Primary care appointment availability and nonphysician providers one year after Medicaid expansion. Am J Man Care. Online (Bergh). 2016;(June):17.

18. Bodenheimer $T$, Sinsky C. From triple to quadruple aim: care of the patient requires care of the provider. Ann Fam Med. 2014; 12(6):573-576.

19. Sinsky CA, Willard-Grace R, Schutzbank AM, Sinsky TA, Margolius $D$, Bodenheimer $T$. In search of joy in practice: a report of 23 high-functioning primary care practices. Ann Fam Med. 2013;11(3):272-278.

20. The Kaiser Family Foundation. 2015 Employer Health Benefits Survey. www.kff.org/health-costs/report/2015-employer-healthbenefits-surveyl. Published Sep 22, 2015.

21. Fisher ES, Lee PV. Toward Lower Costs and Better Care-Averting a Collision between Consumer- and Provider-Focused Reforms. N Engl J Med. 2016;374(10):903-906.

22. Brot-Goldberg ZC, Chandra A, Handel BR, Kolstad JT. What does a deductible do? The impact of cost sharing on health care prices, quantities and spending dynamics. NBER working paper 21632. Washington, DC: National Bureau of Economic Research, 2015. 